\title{
Culinaria y territorio: entre la comoditización y patrimonio
}

\author{
Beatriz Cid A.*, Sandra Fernández C.**, Noelia Carrasco H.**** \\ Universidad de Concepción (Chile)
}

\begin{abstract}
Resumen: El texto reflexiona en torno a un proyecto de Investigación-Acción Participativa de turismo culinario basado en la puesta en valor del patrimonio alimentario campesino e indígena, desarrollado en el Sur de Chile. Desde ahí, se reflexiona en torno a la turistificación del territorio y los alimentos, y sus implicancias para la repolitización del lugar. A partir del caso se argumentará que los procesos de patrimonialización y turistificación son heterogéneamente vividos y terreno de luchas por la hegemonía, existiendo el riesgo de hegemonía del saber experto donde se arriesga que la categoría de "lo otro" se imponga sobre la categoría de "lo justo" y se produzcan formas de colonización cultural.
\end{abstract}

Palabras Clave: Turismo culinario; Patrimonialización; Comoditización; Territorio; Otredad; Chile.

\section{Cuisine and territory: between commodification and heritage}

Abstract: The text reflects on a research project-participative event relating to cuisine and gastronomy, in this case, native cuisine in the South of Chile. This led us to reflect on the touristification of territory and food, and its implications for repolitising sense of place. The case study affords a perspective of how the processes of patrimonialization and turistification are heterogeneously experienced and power struggles as a result, existing the risk that the perspective of "the other" be imposed on what is "fair" and produce new versions of cultural colonisation.

Keywords: Culinary tourism; Patrimonialisation; Commoditisation; Territory; Otherness; Chile.

\section{Introducción}

El turismo experiencial ha aparecido crecientemente como propuesta de desarrollo para comunidades campesinas e indígenas, gestada desde las propias comunidades o bien desde organismos de promoción, ONG, gobiernos y el mundo académico (Murphy 1985; Murphy \& Murphy, 2004). En la construcción experiencial, la culinaria juega un rol central, haciendo del turismo un espacio de manifestación tanto de la otredad como de la comensalidad; la producción de la diferencia como atractivo turístico y el encuentro en torno a la mesa, que aparecen como elementos centrales en dicha experiencia. El turismo se expresa así como un espacio de encuentro entre distintos: el visitante es quien observa, se divierte, paga, se mueve a lugares distintos; y quién es visitado, que acoge, recibe dinero, trabaja y permanece en el lugar. Uno es portador de interés y dinero, el otro es portador de sus propios intereses y de patrimonio para mostrar. La culinaria, así mismo, es tanto el espacio de la comensalidad -el compartir, el reconocerse como iguales- como también el espacio de producción de la diferencia: lo que comemos nosotros en relación a lo que comen los otros.

El presente texto es una reflexión en torno al proyecto "Desarrollo del Arca del Gusto en Chile, Bases para el Fomento del Turismo Culinario Comunitario" desarrollado entre los años 2012 a 2015 en el Sur de Chile. Dicho proyecto tuvo como objetivo "Contribuir al desarrollo de turismo culinario basado en la reactivación, conservación y puesta en valor del patrimonio alimentario y en la promoción de comunidades del alimento en localidades rurales de Chile". El proyecto se desarrolló en dos etapas

\footnotetext{
* Universidad de Concepción; Chile; E-mail: beatrizcid@udec.cl

** Universidad de Concepción, Chile; E-mail: sandrafernandez@udec.cl

*** Universidad de Concepción, Chile; E-mail: noeliacarrasco@udec.cl
} 
de trabajo, primero la identificación y catálogo de alimentos de interés patrimonial. Posteriormente se trabajó en forma participativa en la construcción de circuitos de turismo culinario que permitan a las comunidades la valoración de sus productos en el mercado del turismo experiencial, los cuáles fueron plasmados en un Atlas Culinario Comunitario. Desde ahí se reflexiona más ampliamente en torno a la turistificación y exotización del territorio, la re-construcción del alimento lento y las dinámicas de construcción de la otredad en la búsqueda de repolitizar el lugar.

Participaron de este proyecto organizaciones de distinta naturaleza. Los mandantes fueron la Asociación Nacional de Mujeres Rurales e Indígenas - ANAMURI, la principal organización política del mundo campesino en Chile y única de base femenina - y el Consejo Nacional de la Cultura y las Artes - institución del gobierno de Chile con rango ministerial ocupado de promover el desarrollo cultural, incluyendo la preservación, promoción y difusión del patrimonio. El ejecutor del proyecto fueron las Facultades de Ciencias Sociales y de Arquitectura, Urbanismo y Geografía de la Universidad de Concepción -residencia institucional de las investigadoras que escriben este texto-, dos ONG, el Centro de Educación y Tecnologías para el Desarrollo del Sur (CETSUR) y el Centro de Investigación en Medicina y Agroecología (CIMASUR), de amplia trayectoria en el trabajo con el mundo campesino, y la Fundación Slow Food para la Biodiversidad. Slow Food, organización de raíz europea y reconocida trayectoria en temas alimentarios.

En particular, este escrito se detiene en tres momentos del devenir del proyecto, que constituyen ventanas para el desarrollo de una discusión en torno al turismo y la culinaria como ejes del desarrollo local. Estos tres momentos son primero, el momento de catálogo, por el cual un grupo de investigadores busca la diferencia alimentaria, relevando -desde ojos externos y diálogo con conocimientos locales- una "cocina otra" portadora de un tiempo lento frente al rápido tiempo urbano. El segundo momento refiere al proceso de investigación participativa, realizada a través de una serie de talleres de cartografía social desarrollada por cocineras tradicionales y pequeños oferentes de servicios turísticos campesinos e indígenas, a través de los cuáles se relevó la culinaria y las prácticas agrícolas tradicionales que las localidades desean mostrar. Estas quedaron finalmente plasmados en un Atlas que muestra rutas gastronómicas de interés turístico. En este momento los investigadores externos hablaron menos, limitándose a transcribir y organizar el discurso local de la culinaria. Finalmente, un tercer momento remite a la gira desarrollada por un grupo de las cocineras tradicionales al Encuentro de Terra Madre organizado por el Movimiento Slow Food en Turín, Italia, espacio donde se presentan los productos locales -en el marco de muchos otros productos considerados igualmente lentos y exóticos ante la mirada y criterios de actores europeos sensibles a la cuestión alimentaria. Cada una de estas instancias constituye una ventana de observación a la construcción social de los territorios turísticos tercermundistas basados en las culinarias locales y su sentido histórico cultural.

\section{Reflexiones teóricas}

Las reflexiones teóricas se detienen en dos temas centrales y dos categorías transversales. Los grandes temas son (1) el turismo como ejercicio complejo de construcción social de los territorios y (2) la culinaria como espacio a la vez localizado/doméstico y mercancía global de nicho. Las categorías transversales son primero, los procesos de comoditización, esto es la transformación de valores de uso cotidiano y localizado en valores de cambio deslocalizados transables en el mercado; y segundo, los procesos de representación de la otredad -en este caso el paisaje y la culinaria de comunidades campesinas- que es construcción social de la diferencia despojando al representado de su capacidad de autorepresentación. Esto último es especialmente relevante dado el que enfoque Investigación-Acción Participativa (IAP), busca reconocer la relevancia de los discursos y representaciones locales. Ambas dimensiones, comoditización y producción de la otredad aparecen indisociadas, pues la representación de la diferencia por parte de la mirada del turista produce valor de mercado.

Turismo: Experiencia colonial, turistificación y comoditización del territorio. Esta sección discute la "construcción social" de los territorios turísticos, en el sentido que el turismo, como práctica sociocultural, es un 'constructor' de territorio material e inmaterial, llevando a configurar lugares cargados de relaciones de poder, de conflicto, pero también de cooperación y negociación entre actores con disímiles capacidades de agencia. La territorialidad es comprendida como un conjunto de relaciones tejidas por el ser humano con su entorno, individual y colectivamente (Lindón 2002, 2007, 2009). El proceso de territorialización, se construye a partir de la historia de relaciones sociales y objetos en un sin número de combinaciones posibles, por lo que cada lugar será siempre único (Santos 1996). En este contexto, 
el turismo juega un rol fundamental porque entrega un peso valórico a la estructura del territorio, plasmando en él una serie de imágenes, representaciones y discursos (Aliste 2010). Así, es posible observar cómo la llegada de viajeros puede llevar a la consolidación de estereotipos; favorecer procesos de intercambio; o de revalorización del patrimonio local (Cañada y Gascón 2007).

El turismo es la industria de servicios más grande del mundo y el rubro más grande en el comercio internacional (Cordero, 2006). Si bien ha habido una importante democratización del acceso a servicios turísticos, la producción de bienes turísticos, retrata las relaciones geopolíticas, donde la dinámica del capital aprovecha las desigualdades entre países y regiones. Así como las regiones se dividen entreproductoras y oferentes de bienes turísticos - también la (des)igualdad interna de una sociedad puede calcularse en términos de acceso a esos bienes. Desde los ochenta y noventa, el sector se ha vuelto mucho más centralizado a nivel global, donde los países centrales dominan las cadenas de hoteles, aerolíneas, agencias de viaje, operadores turísticos, restaurantes, etc. (Cordero 2006; Cañada y Gascón 2007). En este contexto, es posible observar una relación contradictoria y dinámica entre los países y sectores que producen esos bienes y los que los consumen (Cañada 2015).

El turismo, es una realidad creciente en América Latina, relacionada con el eje económico de la acumulación, en que la cultura y el lugar que ésta habita, se hacen parte de la comoditización territorial. Así el énfasis es puesto en la producción de bienes turísticos que han sido dirigidos por la demanda del visitante (Cordero, 2006). Los países latinoamericanos son principalmente oferentes de servicios turísticos, cada vez más complejizados a medida que avanza la reestructuración económica global. El mercado del turismo se ha segmentado mucho, incluyendo cada vez más diversidad de experiencias relacionadas con la naturaleza, la cultura, la culinaria. El turismo basado en experiencias vivenciales - pilar central del turismo comunitario - es generalmente representado por viajeros con alto poder adquisitivo, que salen en busca de lo nuevo intocado, 'prístino', salvaje y auténtico. Ya no se trata de ofrecer solamente las tres $\mathrm{S}$ (sand, sun and sex); el paquete debe incluir el contacto aparentemente genuino con las comunidades indígenas y campesinas.

Pensando en el modelo de relaciones laborales que envuelve las actividades turísticas en los países y regiones pobres, es importante subrayar el nivel de informalidad en que éstas germinan; es ésta una de las dificultades para que estos servicios puedan ser vendidos por quienes los producen. (Cordero 2006; Almeida y Cordero 2017). El turismo no es solo un proceso de economía política, sino también un ejercicio de reorganización socioespacial y transformación cultural: una industria productora de espacios, significados y experiencias. Como tal genera un proceso de mercantilización o comoditización de los lugares, que se expresa en la imaginación social, formas de representación cultural y prácticas de consumo (López 2010).

En el proceso de turistificación del territorio, en parte problematizado por John Urry (1990), la mirada del turista es primordial para crear un atractivo turístico (Larsen 2014); así, los lugares se transforman en "artefactos históricos" (Sunyer y Brenner 2011), son motivo del viaje turístico, donde un conjunto de actores sociales externos y locales, intervienen también para hacer de ese lugar específico un objeto creado para el turista. El lugar - territorio habitado y vivido- es entonces

"[Un] elemento y un factor, porque ambos coexisten, y que entabla un diálogo, primero, con el sujeto, o los sujetos, que lo visitan... otros actores...tendrán potestad para designar la función correspondiente al territorio turístico. Porque, en realidad, de lo que se trata en última instancia es de asignar al territorio, a los lugares, la función que en un momento concreto mejor desempeñan de cara al modelo económico, social y territorial vigente" (Sunyer y Brenner 2011, p.178)

Urry (1990; Urry \& Larsen 2011) define el turismo como una práctica moderna de ocio racionalizado y transitorio, opuesta al mundo del trabajo regulado y organizado, que consiste en mirar lugares examinados y escogidos con anticipación. La "mirada del turista" (tourist gaze) se estructura junto a nuestras experiencias; éstas a la vez son construidas por la preexistencia de imágenes culturales generadas por el cine, la televisión, la literatura, la prensa, la música, los videos, etc. Allí se producen nuevas mercancías culturales que se presentan a los turistas como parte de sus expectativas, dependiendo de dimensiones como las estructuras de clases, los géneros, las edades, las identidades étnicas y/o nacionales, los gustos, etcétera. Así, la mirada del turista está dirigida históricamente a observar y experimentar ciertas características de los lugares, que son coleccionados, registrados, apropiados y reconocidos. La obra de Urry (1990) se fundamenta en la noción de poder de Foucault, es decir, cómo crear una situación estratégica para dirigir las acciones de las personas; en el caso del turismo, se trataría de la mirada y el deseo de experimentar vivencias placenteras, estimulantes y exóticas. Los 
lugares a visitar son construidos, diseñados como una oferta mercantil. El territorio como totalidad se construye en base a relatos, revistas, la televisión; la industria del transporte ha establecido ya las redes para el flujo masivo de turistas. En este texto, ponemos énfasis no sólo en el aspecto de la producción de imágenes y relatos en el proceso de turistificación territorial, sino también en la forma cómo el poder estructural contribuye a la conformación de nuevas formas económicas y de organización del trabajo que combinan su participación en el mercado con prácticas de intercambio basadas en el autoconsumo y la reciprocidad (Harris, 2009).

Queremos también problematizar el proceso de construcción de la belleza turística al turistificar el territorio. Muchas veces, las comunidades que habitan lugares cautivadores para los visitantes, no siempre forman parte de ese proceso y son más bien invisibilizadas. Así también, los habitantes del lugar no necesariamente reconocen valor en el paisaje natural y cultural que siempre han habitado: si siempre han sido periferia y muchas veces pobres, no siempre entienden por qué ahora aparecen como espacio interesante de atracción de visitantes, ni tampoco el interés que hoy despiertan sus productos y preparaciones (Guzmán-López, Borges y Castillo-Canalejo, 2011). En América Latina, la estética naturalista entrega un valor supremo a lo virgen o salvaje; el juicio acerca de lo bello es socialmente ratificado. En el caso de las regiones pobres, es el empresariado quien interpretará los cambios de los gustos turísticos a nivel global y local, y diseñará experiencias acorde a esas nuevas demandas. Los visitantes y usuarios de los servicios turísticos ratificarán o no las valoraciones realizadas por el empresariado. Lo bello natural muchas veces se modifica de acuerdo a las transformaciones en los gustos de los visitantes, de manera que lo bello natural deviene en lo bello construido, o lo bello para si (Cordero 2006).

Culinaria y geografía de los tiempos lentos. Si entendemos el tiempo y el espacio como construcciones ligadas a procesos y prácticas sociales, vemos cómo el capitalismo ha construido una determinada concepción de los mismos. Esta concepción se caracteriza por una compresión espacio/temporal hegemónica, que borra o minimiza prácticas alternativas y otros usos socio-espaciales. Esto es, crea un espacio socialmente homogeneizado. Sin embargo, muchas prácticas y "movilidades" obscurecidas por esta espacio-temporalidad hegemónica, se producen y reproducen en los tiempos lentos. Estas "cotidicionan" - hacen cotidiana- la geografía de los tiempos lentos (Nogué y Romero 2006; Nogué 2014). Nos referimos acá por ejemplo, a prácticas cotidianas de crianceros, pastores o productores a pequeña escala.

El espacio de la alimentación está compuesto por una gran y compleja heterogeneidad; mezclando lo orgánico y lo inorgánico, lo material y lo simbólico, lo social y lo natural (Murdoch, 2006). Asimismo la alimentación es un escenario en el que grandes esfuerzos se están haciendo para proteger los componentes naturales de los alimentos en contra de la industria de "sustitución" y "apropiación" (Goodman et al. 1987). La cuestión de la alimentación es ya un sector completamente politizado y espacializado donde la producción alimentaria de masas ocupa extensas áreas del territorio. Del mismo modo, el consumo de alimentos tiene lugar en espacios culturales diferenciados. Por lo tanto, el esfuerzo para industrializar o desindustrializar los alimentos debe ser planteado espacialmente. En términos binarios, podemos rastrear la aparición de dos espacios alimentarios que por una parte están en pugna ético política, convergen territorialmente: por un lado, los espacios industrializados y estandarizados que están sujetos a procesos de continuas innovaciones tecnológicas en consonancia con los principios de eficiencia económica, por el otro lado, diversos espacios locales de alimentos que mantienen adhesión a los procesos de larga data de producción y consumo, profundamente arraigados en las culturas locales y la naturaleza (Espeitx 2004; Murdoch 2006)

Ambos espacios -el agroindustrial y agroartesanal- coexisten y se hibridizan en el mercado de alimentos contemporáneo bajo la forma de nichos de consumo, sin embargo las contradicciones ético-políticas escalan en la producción de grandes volúmenes y alto valor. Por ejemplo, los alimentos industrializados desafían las nociones convencionales de calidad y justicia que han sido establecidas alrededor de métodos tradicionales y "naturales" de las producciones, mientras que la reafirmación de otros alimentos implica un alejamiento de tecnologías industriales y el re-descubrimiento de procesos de producción más típicos o auténticos. En resumen, los diferentes segmentos del sector de la alimentación parecen ser la partida de las trayectorias opuestas de desarrollo, algunos hacia una aplicación más refinada o intensiva de la ciencia y la tecnología (por ejemplo, los alimentos modificados genéticamente), y otros hacia un nuevo compromiso con los métodos tradicionales de producción (por ejemplo los alimentos, orgánicos y tradicionales) y con el bienestar de las comunidades tradicionales.

Los McDonald aparecen como la ilustración arquetípica de la industrialización y estandarización alimentaria, ofreciendo un producto uniforme desde un sistema de suministro de alimentos fuertemente controlada, lo que permite surgir una red de alimentos realmente globalizados. En contraste, el mo- 
vimiento "Slow Food" (comida lenta), tiene como objetivo reafirmar el valor de los diversos alimentos locales, haciendo hincapié en que las cocinas deben reflejar normas, prácticas y ecologías diferenciadas en lugar de algún modelo normalizado de la entrega de alimentos. La variación de la cocina de comida lenta va de la mano con la variación espacial. Por lo tanto, la red trabaja para fortalecer las culturas y entornos asociados con la producción local y las prácticas de consumo. Así, en lugar de unir áreas locales en un conjunto normativo de las relaciones espaciales uniformes, la comida lenta promueve autonomía, fluidez y complejidad dentro de los espacios de estas propias redes (Murdoch, 2006).

El consumidor "lento" estaría cada vez más fuertemente vinculado no sólo a la comida en sí, sino a los contextos espaciales de la producción de alimentos, saboreando las diversas propiedades de los alimentos, y adquiriendo conocimientos acerca de la ecología y asociaciones culturales en torno a la producción de alimentos, lo que involucra un nuevo compromiso con la alimentación. Estos procesos han venido siendo concebidos como nuevos sentidos asignados a las comidas locales, asociados a valores que son sintetizados a través de la idea de patrimonio cultural y por tanto, implicados en procesos de patrimonialización. El origen de estos procesos se encuentra en consumidores críticos y responsables que, además de procurar la superación de modelos de producción y consumo industrial, buscan relevar los valores nutricionales y simbólicos de las comidas tradicionales. Cuando este proceso se articula con reivindicaciones locales asociadas a la biodiversidad, el reconocimiento cultural y la superación de los problemas que afectan a las economías de subsistencia, se produce el encuentro virtuoso para que actores y comunidades locales validen en la patrimonialización un espacio de desarrollo. De acuerdo a Espeitx (2004) "a través de la patrimonialización se representa simbólicamente la identidad colectiva, y este es sin, duda, uno de los sentidos de construir patrimonio" (p. 195), es decir, contribuir a la creación de relaciones más respetuosas de la diversidad. No obstante, tal y como apunta también la autora, el turismo ha permitido comprobar que las culinarias tradicionales cumplen un rol aún más determinante, no sólo en lo relacional sino también en lo económico y en lo político. Es decir, los procesos de patrimonialización de las comidas locales pueden integrar en sí mismos la reivindicación de derechos, la recuperación cultural y al mismo tiempo favorecer el acceso a mercados a través de la puesta en valor de recursos culturales. Se agrega a ello lo propuesto por Medina (2017), en relación a la dimensión política de la activación patrimonial, pues desde su perspectiva

"[ ] el patrimonio no existe más que cuando es activado desde determinadas instancias. La iniciativa de activación patrimonial puede corresponder a los ámbitos oficiales, o bien surgir directamente de la sociedad civil; sin embargo, aun en este último caso, debe de contar con el apoyo, más o menos explícito, de los poderes o los contrapoderes. Sin poder, no hay activación patrimonial y, por tanto, no hay patrimonio" (Ibíd., p. 2).

En síntesis, la patrimonialización de las cocinas locales dependerá de los intereses que motiven o apoyen el proceso de puesta en valor, lo que en el caso del proyecto analizado se vio especialmente marcado tanto por la presencia del Estado como financista y promotor del desarrollo económico de territorios empobrecidos, como por el reconocimiento que cocineras y comunidades hacen de esta instancia como una oportunidad para emprender.

Ahora bien, las prácticas socioespaciales del movimiento Slow Food no han estado exentas de controversia. Pilcher (2008) señala que la disponibilidad de buenas comidas tradicionales regionales a precios moderados, solo se sostiene a través de prácticas de autoexplotación fuertemente genderizadas. La utopía Slow Food responde a necesidades de consumo de clases acomodadas, a la sobrevivencia de culturas alimentarias campesinas, y no necesariamente a las necesidades del proletariado urbano escaso en dinero y tiempo para la preparación de alimentos. Leitch (2010) agrega que al visibilizar y valorar alimentos tradicionales, productos comunes en la dietas locales son ahora resignificados como alimentos gourmet; estos son trasladados desde las economías domésticas a la circulación de mercancías de alto valor. De esta manera quienes tradicionalmente tuvieron acceso a dichos alimentos, arriesgan quedar ahora excluidos de su consumo. Y todo ello en una narrativa de localización y diversidad cultural que arriesga caer en una retórica de nostalgia nacionalista. Lotti (2010) describe en las prácticas de Slow Food una tensión entre por una parte, tendencias a la comoditización de alimentos y procesos que pasan a ser estandarizados y puestos en el mercado; y por la otra, tendencias a una efectiva salvaguarda de la diversidad social y agrícola en las que participan organizaciones de productores. Miele y Murdoch (2002) destacan las políticas de estetización asociadas a estos procesos.

Ahora bien, es necesario relativizar la pregunta por la comoditización. Appadurai hace varios años (1991), argumentó que la vida social de las cosas -y los territorios- puede adquirir muchas formas, entre ellas la de mercancía (o commodity), esto es, los objetos transitan desde ser definidos por su 
valor de uso (como por ejemplo la habitabilidad o su uso culinario) a ser definidos por su valor de cambio, esto es intercambiable por dinero e inserto en el mercado. Así los objetos entran y salen de su categoría de mercancía. Ello marca la diferencia entre un territorio -o un objeto culinario- habitado o producido para su uso comunitario, o producido para su venta. Mientras los objetos no comoditizados están organizados por usos disimiles, singularizados o incluso opuestos; la comoditización involucra cierta estandarización para su intercambiabilidad abstracta (Lotti, 2010). El proyecto de Slow Food, apuesta a la singularización de las prácticas y relaciones productivas y alimentarias, teniendo como horizonte de acción, estrategias tendientes a rescatar variedades y prácticas productivas desplazadas por la agricultura mercantil. Sin embargo Lotti (2010) argumenta - a partir del caso de la crianza de cerdos vascos- que estas mismas prácticas de diferenciación productiva contribuyen a la creación de mercancías de nicho, altamente diferenciadas y estandarizadas. En otras palabras, no es posible establecer una distinción transparente entre comoditizado y no comoditizado, y en consecuencia tanto las mercancías como las prácticas productivas de los objetos y los espacios transitan entre ambos polos. Así también se problematiza la oposición entre convencional y alternativo, sugiriendo que antes que sistemas opuestos, ambos están fundamentalmente interrelacionados.

\section{Notas metodológicas}

El documento presente texto, proviene de un ejercicio de reflexión crítica posterior a un trabajo de inspiración en la Investigación-Acción Participativa en torno al turismo comunitario del Centro Sur de Chile.

La IAP responde a una larga tradición que problematiza de diversas maneras la relación entre producción científica y comunidad. Primero, fuertemente influida por la pedagogía freiriana (Freire, 1969, 1975, 1997), problematiza y tensiona la relación entre conocimiento experto y conocimiento popular, buscando espacios de diálogo, simetría y sinergia entre ambos. Ello salvaguardando no solo la valides del conocimiento local sino también su vital relevancia para la comprensión de realidades territoriales complejas. El trabajo de Martínez Alier (2005) sobre el saber ambiental de los pobres, es ejemplo de este tipo de aproximación. Segundo, reflexiona acerca del compromiso político que los procesos de investigación deben tener con las comunidades con las cuáles colaboran. Las comunidades no pueden ser reducidas a espacios de "extracción de información" -, sino que el mismo proceso de investigación debe estar organizado a partir del sentido político de las comunidades para su empoderamiento como actores de su desarrollo y el abordaje de sus problemas específicos. Como tal, privilegia formas de investigación aplicadas que permitan producir y devolver conocimiento nuevo con las comunidades (Balcazar, 2003). Finalmente, la IAP hace una reflexión epistémica crítica sobre la distancia sujeto/objeto de investigación y el ejercicio de construcción de la otredad que ello significa. Hablar del otro y por el otro, es un ejercicio de representación y violencia epistémica que vulnera el derecho y la capacidad de las comunidades de hablar por sí mismas (Spivak, 2009). Es por ello prioritario reconocer a todos los participantes como productores de conocimientos y afinar las capacidades de comunicación entre los actores diversos que forman parte del proceso de investigación acción.

En modelos contemporáneos de trabajo participativo, este proceso es concebido como de participación extendida (Funtowicz y Strand, 2007) en el cual los saberes científicos son desafiados a dialogar horizontalmente con los saberes locales en torno a los ecosistemas y las culinarias. Este desafío epistemológico y político fue especialmente importante en el desarrollo de la experiencia, pues sentaba las bases éticas y científicas del trabajo a realizar. Se materializó de diversas formas: a través de la co-organización de las actividades - talleres y giras - con las propias organizaciones locales, a través del uso del diálogo como principal estrategia de trabajo en las sesiones del programa de formación, y a través de la co-autoría del Atlas Culinario Comunitario que sirvió como cierre al proceso implementado.

El proyecto "Desarrollo del Arca del Gusto en Chile. Bases para el fomento de turismo culinario comunitario", en adelante "Arca del Gusto", buscó en sus distintas etapas de trabajo cautelar el trabajo colaborativo y simétrico entre el equipo académico y las participantes de las comunidades. De hecho ANAMURI - la organización política nacional de mujeres campesinas e indígenas- actuó como "mandante" del proceso de investigación y como tal tuvo participación en el diseño y control del proceso. Así también, tanto en las etapas de catálogo e identificación de productos de valor patrimonial como en la etapa de construcción de circuitos de turismo culinario, se trabajó con metodologías participativas que facilitaran el diálogo entre actores, y que subordinaran los objetivos del ejercicio a los intereses de las personas participantes. Cada una de estas etapas es abordada en las dos primeras ventanas del texto. Y en las 
ventanas del documento se problematiza si las cautelas y métodos trabajados lograron efectivamente prevenir el ejercicio de violencia epistémica o si por el contrario ésta se filtra de distintas formas. La tercera ventana describe la participación del grupo en el Encuentro de Terra Madre del Movimiento Slow Food en Turín. En su escritura se plasma tanto la observación etnográfica de una de las autoras como también un conjunto de discusiones desarrolladas por la delegación chilena participante en el encuentro. Como se mostrará, esta tercera experiencia muestra en forma dramática el ejercicio de construcción de otredad que se asocia al turismo y la culinaria tradicional.

\section{Tres ventanas de análisis al "Arca del Gusto"}

Primera ventana: el proceso de catalogación del Arca del Gusto. En esta etapa del proyecto se articularon un dispositivo de Slow Food "El Arca del Gusto", con un conjunto de saberes expertos locales respecto de la agricultura y culinaria tradicional, y la mirada selectiva del grupo de investigación, cada uno de ellos portando una carga de significación necesaria de manejar.

El Arca del Gusto, constituye uno de los dispositivos políticos y simbólicos centrales de Slow Food. En palabras del propio movimiento

El Arca del Gusto es un catálogo de productos que pertenecen a la cultura y a las tradiciones de todo el mundo y que están en peligro de desaparición. A bordo del Arca suben especies vegetales y animales, pero también alimentos transformados, puesto que, junto a la biodiversidad vegetal y animal, desaparecen asimismo quesos, embutidos, panes, dulces: expresión de saberes campesinos y artesanos no escritos, pero complejos y cargados de prácticas y capacidades transmitidas durante generaciones (...) El Arca nace para señalar la existencia de estos productos, denunciar el riesgo de su desaparición, invitar a todos a hacer algo para salvaguardarlos: buscarlos, comprarlos, comerlos, describirlos, ayudar a los productores y, en algunos casos (cuando los productos son especies silvestres en peligro de extinción), tutelarlos y favorecer su reproducción (Slow Food, s.s. pp 4 y 5).

La metáfora del Arca releva el rescate de productos de la culinaria tradicional frente al diluvio catastrófico representado por la agricultura industrial. La misma metáfora resultó ser contenciosa en contextos poscoloniales (Lander, 2000), como lo señaló abiertamente un dirigente mapuche en una actividad pública del proyecto: una alegoría bíblica tiene un carácter fuertemente eurocéntrico incapaz de representar otras sensibilidades. Este elemento representa una tensión del dispositivo: es el mundo occidental quien construye un arca para salvar los mismos alimentos amenazados por el diluvio de una forma también occidental de desarrollo.

El proceso de investigación para la elaboración del catálogo remitió a revisión de fuentes -tales como libros de recetas, libros de razas animales, etc.-, visita a bancos de germoplasma (como el banco de germoplasma de papas) y entrevistas y visitas a diversos investigadores e informantes clave (veterinarios, agrónomos, ONG, cocineros tradicionales, gastrónomos). Hay aquí un primer ejercicio de selección, pues estos informantes clave, no son necesariamente portadores fieles de la memoria colectiva de una comunidad. Por ejemplo, la experiencia del Banco de Germoplasma Chileno de Papas (de la Universidad Austral de Chile), que ha logrado catalogar alrededor de 200 variedades de papas chilotas en riesgo por la pérdida de sistemas productivos tradicionales y que sin embargo no logra mantener totalmente una relación de confianza con las comunidades de productores. Proceso similar sucede con estudiosos de la avellana y los quesos, que comprenden dichos productos como separados de sus comunidades de alimento: las avellanas nativas en relación a la industria cosmética, y los quesos como un producto a ser estandarizado y mejorado según estándares y recetas europeas. Finalmente, investigadores nombraron "superalimentos" como el Liuto - la raíz de la astromeria, una flor del bosque- la cual sin embargo no es reconocida como alimento real por ninguna comunidad del territorio.

Así mismo, el equipo de investigación hizo un segundo proceso de análisis de las entrevistas, que implicó la selección -y normalización- de la información señalada por los informantes clave. En este segundo análisis, se descubre la existencia de especies que poseen una evidente doble valoración. Ejemplo de ello es la zarzamora y sus elaboraciones, reconocida por algunas cocineras locales como un producto tradicional que es necesario proteger, y evaluada por los investigadores como una plaga invasiva introducida por la colonización europea que daña la tierra agrícola.

Estos ejemplos muestran como el proceso de construcción del catálogo es un proceso dialógico en el cual se negocian diversos saberes y construcciones políticas. Así mismo se evidencia que la revaloración 
de la culinaria tradicional por parte del mundo urbano es parte de un proceso mayor de revalorización de los espacios "lentos del comer". Actores políticamente informados buscan y encuentran en la cocina del mundo campesino aquello perdido por los procesos de industrialización de la cadena alimentaria: lo diverso, lo agroartesanal, lo ecológico, lo familiar. Por su parte, el mundo campesino, revalora sus propias prácticas en relación a esta mirada urbana y global.

Segunda ventana: los talleres. Luego del ejercicio del Arca del Gusto, el proyecto emprendió un proceso de creación colectiva de rutas culinarias comunitarias centradas en la valoración de productos tradicionales. Estas rutas buscaron articular distintos actores que trabajan en torno al producto: productoras y recolectoras, elaboradoras y cocineras del alimento. Para ello se diseñó una metodología que integrara el diseño de rutas, con un proceso de formación en temas de turismo, el cual culminó con la elaboración de un Atlas Culinario Comunitario de co-autoría entre participantes locales e investigadores/as.

El Atlas nace de la implementación de una metodología que permitió acercase a la escala de la cocina tradicional a través del mapeo colectivo. El mapeo colectivo, como herramienta teórica - metodológica de las cartografías sociales y cartografías participativas, es una forma otra de construir y entender las distintas espacialidades y representaciones presentes en cada territorio (Diez Tetamani y Escudero 2012). Busca el dialogo de otras realidades, mediante la visibilidad de una serie de sucesos, lugares y personas antes ignoradas. Construido de manera horizontal, el mapeo colectivo, incorpora a la construcción de los mapas las visiones, aprensiones, significancias, sanciones y necesidades de quienes lo construyen. En este sentido, hablar de mapeo colectivo, es hablar de la acción colectiva de hacer. Acción que se materializa en una relectura del territorio, en donde quien decide, traza y dialoga en y con el mapa, son las personas de la comunidad (Vélez, Rátiva y Varela 2012; Diez Tetamani y Varela 2012) Se trabajó en talleres y terrenos, tanto en la cordillera de Nahuelbuta como en el cordón Llanquihue y Chiloé; en las jornadas se trazaron los distintos territorios -vinculados a la investigación- reconociéndose en ellos los componentes ambientales y culturales presentes.

Las comunidades vinculadas se encuentran localizadas entre la región del Biobío y la región de Los Lagos, principalmente en zonas rurales de agricultura campesina y el uso de semillas recuperadas ${ }^{[1]}$. En cuanto a sus cocinas, éstas se caracterizan por estar basadas en productos de cultivo y recolección local, los que son conservados y preparados sobre la base de recetas memorizadas y aprendidas en cada hogar. Nuestra reflexión se sustenta en el análisis del intenso y enriquecedor proceso de trabajo en los talleres de cartografía social coordinados durante un año por el equipo de investigación del proyecto. Para los fines de este texto, queremos rescatar algunas temáticas emergentes que surgieron de la forma colectiva de generación de conocimiento que conforman el pilar de la investigación participativa:

1) Valorización /desvalorización de las prácticas tradicionales. La primera entrada al proceso de revalorización de la economía local, se desarrolló a través de una muestra de culinaria por el cual se invitó a cocineras locales - desde dueñas de casa hasta cocinerías y microempresas de catering-a recuperar recetas familiares antiguas, y elaborarlas en su totalidad con productos campesinos del territorio. Esta muestra terminó con una premiación de los platos más destacados y una exposición de los productos. Posteriormente las mismas participantes fueron invitadas a cartografiar su territorio culinario. Este fue un ejercicio denso de revalorizar la práctica privada y genderizada de la cocina, especialmente en su vertiente tradicional (en oposición a la cocina experta gourmet). En esta oportunidad, se repitieron muchas veces frases como "nunca había valorado lo que hacía", "yo no me daba cuenta", "yo era la vieja y ahora soy valorada". Estas frases visibilizan que el ejercicio de valoración está mediado por la mirada de los otros, permitiendo relevar en este contexto, la dimensión intersubjetiva de lo valioso.

2) Valorización/desvalorización del trabajo colectivo: El ejercicio de mapeo participativo, obliga a pensar en términos colectivos y territoriales. Asimismo, pensar en términos de ruta responde a un objetivo ideológico de promover emprendimientos cooperativos y un objetivo de mercado de asegurar productos turísticos más complejos que involucren distintas actividades en torno al producto - como por ejemplo acompañar expediciones de recolección en bosque o cultivo en huertas, presenciar la elaboración (ahumado, conservería, etc.) y finalmente acompañar y disfrutar de la cocina y consumo del producto-. Este ejercicio mostró una gran dificultad para pensar el turismo en términos comunitarios, pues cada uno posee un recurso y cuesta pensar en términos de un lugar que es habitado colectivamente. La instalación de cierta lógica de competencia logró traspasar los anhelos y sentidos de trabajo compartido. Los ejes de acumulación del capital transforman el 
territorio en recurso; las disputas sobre qué recurso es más valioso, más "vendible" atraviesa los proyectos y reafirma la visión de una necesidad de construcción de la valorización mutua.

3) Tensiones generacionales en los procesos de comoditización: Las portadoras de un valor turístico -conocimiento culinario- son generalmente mujeres mayores. Sin embargo, su propia experiencia no se articula con el turismo como práctica comercial, no se visualiza como un "verdadero" trabajo, sino más bien como parte de su cotidianeidad. Son los jóvenes quienes están más abiertos a ello; pero en general, no son portadores de ese saber. Relevamos aquí las dificultades para establecer vínculos intergeneracionales a nivel local. Desde ahí -y en un proyecto de continuidad- se pensó en dos figuras centrales: las cocineras tradicionales, portadoras de la experiencia y el saber de la culinaria tradicional; y los gestores de turismo culinario; personas -en su mayoría más jóvenes- capaces no solo de hacer la guiatura de los circuitos sino también de desarrollar labores de administración y vínculo digital con el mercado turístico.

Tercera ventana: visita Terra Madre. Como parte de las actividades finales del proyecto, una delegación de cocineras/os tradicionales participó del Terra Madre 2014 desarrollado en Turín, Italia. Terra Madre es un evento bianual del Movimiento Slow Food, desarrollado desde el año 2004, que convoca a representantes de comunidades del alimento de distintas partes del mundo. Se desarrolla en forma paralela al Salón del Gusto (que visibiliza a productores tradicionales y gourmet italianos), en espacios contiguos pero claramente delimitados.

El evento convoca productores agrogastrónomicos de los cinco continentes, y se organiza como una feria con stands por países donde se muestran y degustan productos y especialidades regionales. Además de la degustación se venden algunos productos, los que sin embargo no son vendidos directamente por los productores sino a través de la mediación de Slow Food. De hecho la organización compra previamente los productos directamente a los expositores y se hace cargo del transporte, trámites de importación y distribución de productos excedentes, razón por la cual los productos aparecen muy encarecidos respecto a su precio original, lo que causa extrañeza entre los productores.

Los stands están atendidos por los productores de los países visitantes, generalmente vestidos con atuendos tradicionales y que muchas veces no hablan italiano ni inglés, junto a voluntarios italianos de Slow Food, que hacen el trabajo de traducción lingüística y muchas veces reinterpretación sociocultural (por la cual el discurso de los productores puede quedar silenciado por el relato de los interpretadores). La Feria está organizada espacialmente de acuerdo a pasillos referidos a cada continente, teniendo un lugar central la exposición del "Arca del Gusto" donde se muestran productos agrícolas y elaborados que están en riesgo de desaparición por desplazamiento desde la agroindustria. La Feria es ampliamente visitada tanto por personas que vienen primariamente a ella como por aquellos que visitan el Salón del Gusto, ello hace difícil el tránsito en la feria (dificultando la comunicación entre los productores de los distintos stands, más allá de las barreras idiomáticas) y especialmente recarga de trabajo a los productores que atienden el stand. Contribuye a esta recarga el hecho que los horarios de atención son muy extendidos.

El viaje hacia el encuentro es un evento en sí mismo. Para muchos de los productores ésta es la primera vez que viajan fuera del país y se suben a un avión. De hecho el viaje mismo se vive como una experiencia vital y como una performance. Por ejemplo, una expositora es acompañada al aeropuerto por funcionarios de la municipalidad y otras expositoras viajan con su vestimenta tradicional completa, incluyendo pesada joyería sobre su cabeza. Una vez llegados a Turín son recibidos por voluntarios de Slow Food quienes se encargan de su distribución en alojamientos y de sus necesidades de alimentación. $\mathrm{Al}$ respecto, es muy distinta la situación de los productores quienes se alojan en casas de voluntarios de Slow Food, quienes hacen gala de su hospitalidad, respecto de los acompañantes técnicos, quienes se alojan en hoteles, quedando a la deriva en la ciudad.

La primera actividad del encuentro - que las delegaciones vivieron en la ambivalencia del entusiasmo y el cansancio del viaje- fue un evento de inauguración con presentaciones artísticas y diversos discursos, de miembros de las distintas delegaciones y especialmente el discurso de Carlo Petrini, fundador de Slow Food. Destacan la diversidad de los discursos, desde la presentación de la representante de México, con un claro discurso feminista y crítico a la agroindustria; hasta el saludo vía video de Michelle Obama, quien destaca la promoción de huertas urbanas para la calidad de vida. El discurso de Petrini, de una vertiente crítica enfatizó la relevancia de las personas -y las comunidades del alimento- por sobre el producto. Un hito central de este evento fue el desfile de representantes de las delegaciones visitantes, el que fue hecho en su gran mayoría por personas embanderadas vestidas con atuendos tradicionales. 
El vestuario en sí mismo fue objeto de conversación entre los asistentes por la carga de esencialización y folcklorización que tiene el uso de vestimentas tradicionales entre personas que no la usan ni habitual ni ceremonialmente.

A la hora de las evaluaciones, las delegaciones latinoamericanas valorando profundamente la experiencia de viaje y encuentro que Terra Madre significa, manifiestan también diversos grados de insatisfacción particularmente respecto al contraste y articulación entre Terra Madre y el evento Salón del Gusto, los que aparecen visualmente y espacialmente organizados desde categorías semánticas muy disimiles.

Terra Madre aparece fuertemente etnitizado: los productos, las vestimentas y los lenguajes se presentan desde la categoría de lo exótico y necesitado de "traducción" por parte de los voluntarios. Este ejercicio de traducción puede llegar a ser bastante contencioso, pues en la dificultad de la comunicación los voluntarios terminan monopolizando el habla, mientras los productores quedan silenciosos con sus caras y vestimentas exóticas en el telón decorativo del discurso. Junto a la exotización, predomina también la categoría de "lo justo" como criterio de inclusión: cado uno de los productos expuestos y comercializados debe demostrar su pertenencia a una "comunidad del alimento" donde se salvaguarde el carácter ético, ecológico y agroartesanal de lo producido. Esto es la subordinación de la producción a principios ético políticos.

El espacio del Salón del Gusto, por su parte, se presenta menos politizado y dominado por las categorías de los gourmet -la organoléptica y la presentación de los productos- y el territorio en tanto portador de un terrior. De esta manera, mientras la categoría de "lo slow" en el espacio Terramadre aparece como una categoría política que da cuenta de un conjunto de prácticas productivas, en el espacio Salón del Gusto, "lo slow" se enfoca en el producto -como objeto- invisibilizando las relaciones sociales de producción (que son relaciones entre sujetos). Como consecuencia la pregunta por el tipo de relaciones productivas en las que se elaboran estos productos, estaría relativamente ausente o menos trabajada.

Esta distinción tan marcada entre los dos espacios tiene como consecuencia la introducción en la estética y la práctica de Terra madre de una dimensión colonial, esencializante, erotizante, exótizante y folkclorizante. De hecho en parte de la gráfica desplegada en el evento, las personas mismas pueden ser vistas como apetecibles, un objeto comestible (Figura 1 y 2 ).

Figura 1: Gigantografía desplegada en Terra Madre, 2016.

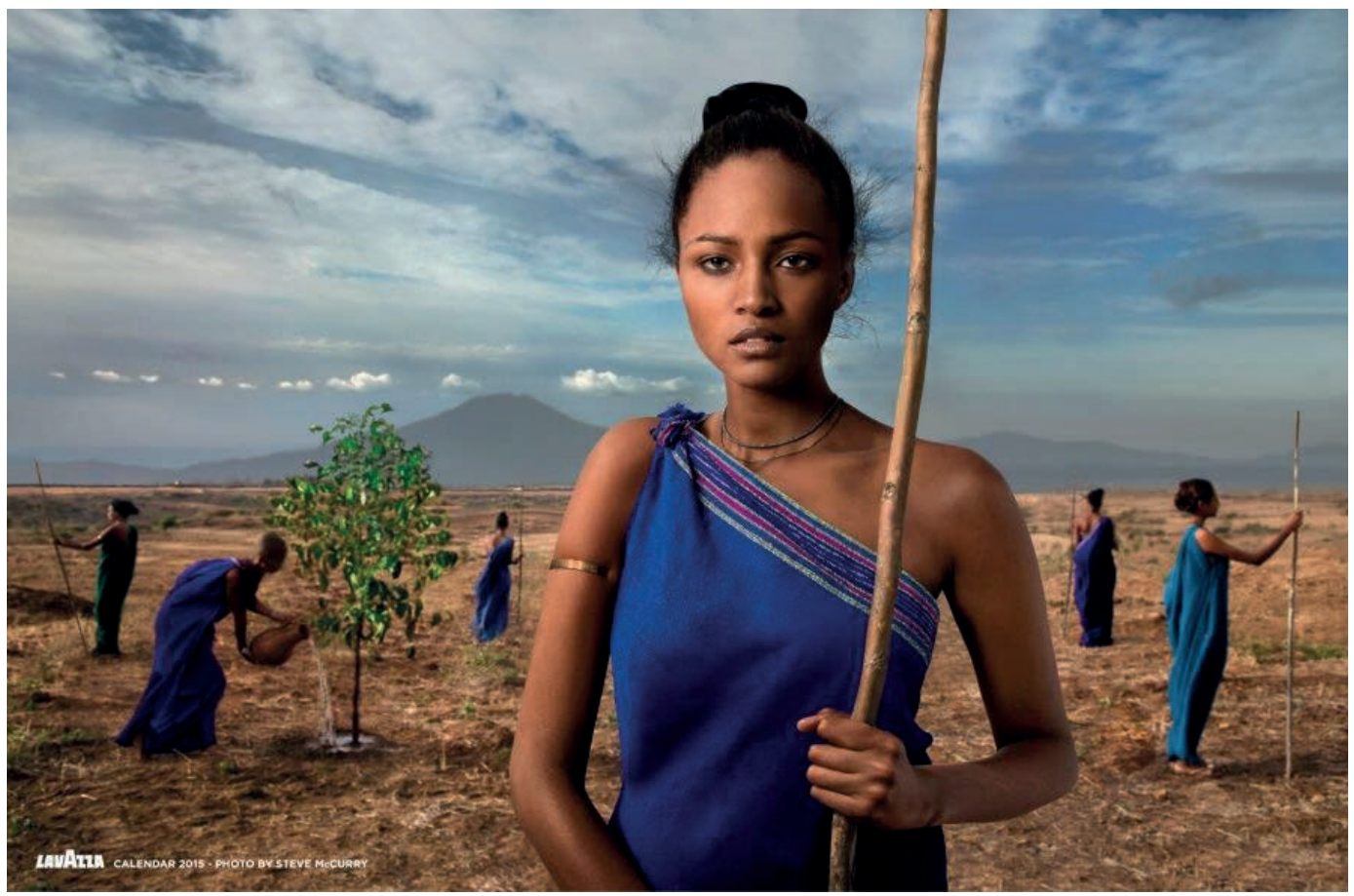

Recuperada de http://www.abouttimemagazine.co.uk/event/lavazza-x-slow-food/ 
Figura 2. Gigantografía desplegada en Terra Madre 2016.

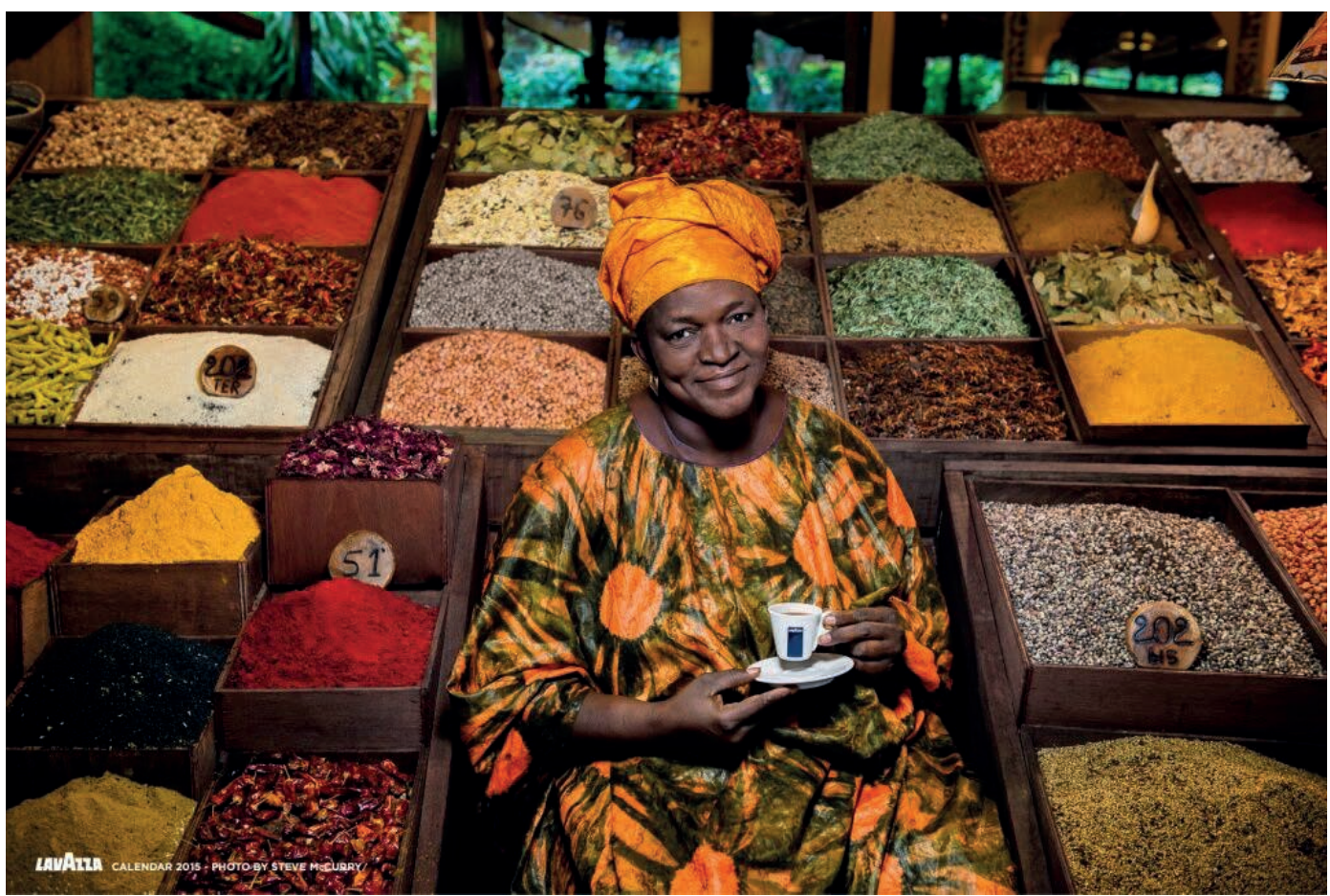

Recuperada de http://www.abouttimemagazine.co.uk/event/lavazza-x-slow-food/

Estas imágenes desplegadas en Terra Madre y el Salón del Gusto., estaban acompañadas de la siguiente leyenda:

The 2015 Lavazza Calendar which has been produced together with Slow Food, features twelve breathtaking pictures by renowned US photographer, Steve McCurry, capturing the spirit, strength and humanity of the Earth Defenders - women and men who protect their land and projects in Africa with passion and bravery. The images will be on display at the international food and wine fair, Salone del Gusto and Terra Madre 2014 (Turin, October 23-27 2014), which is geared towards the Slow Food movement, of which Lavazza has been a sponsor for more than 20 years (www.slowfoodfoundation.com / filemanager /.../SPA_libretto_arca_b.pd)

De esta manera, dominan en la descripción de los productos una estética de la otredad, donde la comodity es evaluada no tanto por su representación de lo justo, sino por su representación de "lo otro".

\section{Reflexiones finales y conclusiones}

Este escrito se detiene en procesos en torno a la culinaria y el turismo que traen consigo importantes desafíos políticos y culturales para comunidades rurales e indígenas del capitalismo periférico. Dichos procesos incluyen la mercantilización de culturas e identidades, y por tanto, de aquellos lugares específicos donde se tejen relaciones entre actores sociales diversos; los territorios se construyen como atractivos turísticos bajo la "mirada" del visitante; el lugar se va configurando por la intervención de visitantes y actores locales movidos por distintos intereses; este lugar puede convertirse en un objeto funcional para la industria del turismo, como también en un catalizador de una reafirmación identitaria o en un centro de actividades socioeconómicas revitalizadoras para regiones periféricas.

Construcción de territorio y diversidad de actores: El proyecto que da sustento a este artículo, fue diseñado e implementado por una diversidad de actores que involucra permanentes negociaciones. Los mandantes del proyecto - el Consejo Nacional de la Cultura y la organización ANAMURI - son 
dos organizaciones de muy distinta naturaleza; sus proyectos están también sujetos a una variedad de discursos sobre lo alimentario, el patrimonio y la economía política de los alimentos. Mientras el Consejo de la Cultura lo define como parte del patrimonio cultural inmaterial de la nación, ANAMURI lo hace desde la densidad de las relaciones productivas campesinas, donde la culinaria es parte de un entramado agrícola, familiar, material y simbólico mayor (irreductible a la noción de inmaterialidad), densidad toda consustancial al sentido de lugar y territorio, donde el turismo puede ser una herramienta para contribuir a la sostenibilidad de las economías campesinas. Así por ejemplo si desde el Consejo de la Cultura tiene sentido el rescate de recetas y platos, para ANAMURI eso sólo tiene sentido en el rescate material y político integral del modo de vivir campesino que da vida a dichos platos. Por otra parte, Slow Food, posee un foco y lenguaje puestos en la recuperación y conservación de los productos y culinaria tradicional en un contexto de apertura económica y globalización cultural, basados en principios éticos que aparecen compatibles con la exotización y folclorización de la otredad. Finalmente, el financista del proyecto, CORFO, cuyo foco y lenguaje se aleja de la pregunta por el patrimonio, se enfoca en el apoyo a procesos de emprendimiento e innovación, por lo cual entiende a la culinaria como un recurso susceptible de ser explotado desde la lógica del turismo; por lo cual entiende a la culinaria como un recurso susceptible de ser explotado desde la lógica del turismo; y donde las expresiones y artefactos de identidad son también recursos disponibles a procesos de comoditización capaces de adquirir valor de mercado.

Esta diversidad de discursos y visiones sobre el proyecto, reflejan que cada lugar es heterogéneamente vivido y terreno de luchas por la hegemonía del habla/discurso. En este contexto, la metáfora del Arca puede no hacer sentido en contextos interculturales, o incluso dar cuenta de nuevas y sofisticadas formas de dominación, donde el centro rescata aquellos recursos de territorios periféricos que le son de utilidad, reafirmando patrones de relaciones no sólo diversas sino también desiguales. Por tanto, comprender al territorio como un tejido de relaciones, constantemente intervenido por ciertas tecnologías de poder/saber que se despliegan para conformar racionalidades dominantes que buscan crear espacios de control sobre los saberes de comunidades campesinas e indígenas a nivel local, supone una tensión entre el diálogo auténtico de saberes y el riesgo de la hegemonía del saber experto. En cualquier proceso investigativo, ciertas prácticas pueden ser invasivas y provocar cambios; esas prácticas tienen el efecto de, por ejemplo, silenciar voces o celebrar otras, al interior de comunidades en que las relaciones sociales de género, clase o generacionales son poco igualitarias.

Frente a ello es necesario reconocer los ejercicios de resistencia y de control cultural, en que la modalidad del turismo comunitario puede permitir la reivindicación de derechos y el debate ecológico político en torno a la naturaleza. No se trata de tomar aspectos de una determinada 'cosmovisión' y agregarlos a un modelo ya construido y comprendido como superior, sino más bien de nuevos modos económicos en que se participa del mercado pero no se depende de él.

Lo anterior, implica el gesto de reconocer, valorar y celebrar el pensamiento y prácticas diversas de los/ as otras/as constructores de territorio a través de las relaciones que se tejen en torno a la alimentación, los productos, alimentos y formas de cocinerías ancladas espacialmente al lugar único y diverso que se ha construido. En este contexto, es importante considerar el ejercicio de inversión de las habituales relaciones de hegemonía discursiva que apunte a reconocer la diversidad de hablas y discursos en el lugar.

Comoditizacion de los alimentos y turistificación del territorio. La comoditizacion es un proyecto de transformación de algunos valores de uso cotidiano a las comunidades -objetos, prácticas y artefactos simbólicos- en valores de cambio transables en el mercado. Este proceso es siempre problemático pero no necesariamente negativo. De hecho la intuición del proyecto es que, mientras sea controlado por actores y comunidades locales, cierto grado de comoditización puede ser positivo para generar las condiciones económicas que sostengan la continuidad de los procesos productivos que mantienen el patrimonio. Asimismo muchos de los actores lo evalúan como una contribución efectiva para el bienestar de las comunidades, en términos de reproducción ampliada de la vida económica y social rural. Ello no lo exime sin embargo de su carácter problemático, particularmente en términos de economía política. Las preguntas centrales son entonces ¿Cómo y quién controla y se beneficia del proceso de producción y circulación de las culinarias tradicionales comoditizadas?; ¿qué se requiere para que el proceso de comoditización sea organizado y controlado a nivel local?; ¿cómo se organizan las experiencias de turismo comunitario basados en el principio de la generación de beneficios colectivos? Y ¿cómo interactúan en la culinaria tradicional el carácter de commodity con las otras dimensiones del objeto: utilitarias y simbólicas?

En este proceso de comoditización identificamos al menos tres tensiones. La primera de ellas refiere a la tensión entre el desarrollo de proyectos individuales de comoditización y las posibilidades de desarrollo de proyectos colectivos. La apuesta por la construcción de rutas territoriales que hace el proyecto es 
parte de un acto de voluntarismo político de quienes lo promueven, interesados en fomentar relaciones cooperativas. Así mismo y como se señaló anteriormente, la incorporación de más actores -recolectores, elaboradores, cocineros- permite la elaboración de rutas más complejas y atractivas. Esta dimensión colectiva, también da cuenta que la producción y consumo de alimentos es siempre comunitaria. Ello no solo por las relaciones de comensalidad sino por la participación en un sistema alimentario común, que articula a productores y cocineros de un territorio. De esta manera la herramienta de las rutas reconoce lo complejo, territorial y colectivo de la conservación y puesta en valor de los alimentos. Ello sin embargo se tensiona con la posibilidad, siempre cierta, que algunos actores puedan tomar un rol protagónico en la gestión de la ruta, desarrollando un proyecto económico desarraigado de la acción colectiva y concentrando una parte mayor de los beneficios.

Una segunda tensión refiere a la ya mencionada relación entre productores y cocineras tradicionales y actores más nuevos en el territorio. Productores y cocineras representan la mantención e historicidad del producto en un contexto adverso, los saberes y las prácticas de una cultura culinaria. Sin embargo, dada la avanzada edad de algunas de estas cultoras tradicionales cabe la pregunta de la reproducción intergeneracional del producto, su preservación -y reinvención- para el futuro, y la gestión de su proceso de comoditización. Surge acá la figura de los que hemos venido a llamar gestores de turismo comunitario, esto es, personas que no estando ajenas al proceso productivo, coordinen y gestionen el vínculo del mismo al mercado, resguardando los principios de cooperación y sentido comunitario.

Una última tensión asociada a este proceso de comoditizacion tiene que ver con el cambio del cocinar como acto familiar, al cocinar "para otros". El cocinar para otros, expone a otras miradas -y otros ejercicios de significación- el acto de producir y cocinar. Entran acá varias miradas, primero la de nosotras como observadoras externas, Slow Food como organización internacional, el Consejo de la Cultura, y posteriormente la mirada de empresarios turísticos (que han visitado el proyecto a través de Tours de familiarización) y ciertamente la mirada del turista. Todos ellos dispositivos de observación que evalúan críticamente el sabor, y sobre todo la estética de lo presentado, y ciertamente pueden conllevar el riesgo de la exotización. Ello pone en duda la libertad que mantienen las comunidades para decidir respecto a la permanencia y modificación del producto. Como ejemplo, el mundo campesino suele usar el mismo tipo de loza y cubiertos que se usan en el mundo urbano, sin embargo la mirada del turista, de la agencia de viajes y del patrimonio demanda la utilización de platos tradicionales de greda. Como López y Marín (2010) señalan, en el proceso de comoditización, el turismo produce mercancías culturales y experiencias que incluyen las representaciones de los "otros" y la reconstrucción de las identidades.

Terra Madre y la producción de la otredad. La categoría de "lo justo" en el discurso de Slow Food - es semánticamente un adjetivo del producto. O sea, agrega atributos, pero no problematiza la complejidad de los procesos de comoditización, por el cual los objetos pasan desde el uso cotidiano a ser producidos para el mercado. En la ausencia de dicho análisis, la producción de la otredad como producto de mercado, se constituye para los productores en una de las pocas opciones que tienen para hacer económicamente viables sus iniciativas productivas. Es por ello, que la promoción de la pequeña producción -lo slow- sin una real problematización del contexto político y económico de los productores, arriesga conllevar a nuevas formas de colonización cultural -ya no como proceso de estandarización de acuerdo a patrones occidentales, sino como folclorización y super-estetización de culturas locales, que parecen en sí mismas como artículos de venta de alta exclusividad en mercados de nicho. Preocupa en este sentido el riesgo de relevar lo exótico, puro y prístino de los lugares turistificados en las periferias del capitalismo tardío. Diversos estudios sobre turismo en el 'tercer mundo' revelan cómo se acentuó el "retorno a la naturaleza" para el turista que demanda y paga por un servicio construido literalmente para él/ella. Esto incluye la creciente "patrimonialización" de objetos, construcciones, productos y también de las personan que habitan esos lugares declarados patrimonio.

Sin embargo, ésta no es la única codificación posible, estando abierta la posibilidad de ser herramienta útil para los procesos políticos de construcción económica local. De hecho, desde las economías campesinas, el discurso y dispositivos de Slow Food devienen en una identidad instrumental para acceder a reconocimiento y recursos, más que una relación sustantiva. Ello se articula con lo oblicuo como estrategia campesina histórica, porque las decisiones de identidad y comoditización de las comunidades son siempre subjetivas, negociables y políticas. De esta manera la afinidad estratégica-nunca identidad- entre dos cuerpos políticos -la demanda por el respecto a la alteridad cultural y económica del mundo campesino-, y la demanda por lo "slow" de raíz urbana y occidental, puede dar frutos ciertamente interesantes que permitan la valoración económica y simbólica de los territorios, sus comunidades y alimentos patrimoniales. 


\section{Bibliografía}

Aliste, Enrique

2010. “Territorio y ciencias sociales. Trayectorias espaciales y medioambientales en debate." En Aliste,

Enrique y Urquiza, Anahi (Compiladores) Medio ambiente y Sociedad (pp. 55-73). Santiago de Chile:

RIL Editores.

Almeida, Paul y Cordero, Allen (Eds.)

2017. Movimientos sociales en América Latina. Perspectivas, tendencias y casos. Colección Democracias en Movimiento. ISBN 978-987-722-244-9. Buenos Aires: CLACSO

Appadurai, Arjun

1991. La vida social de las cosas: perspectiva cultural de las mercancías. México D.F.: Grijalbo.

Ashely, Caroline

2000. The impact of tourism on rural livelihoods: Namibia's experience. Londres: Chameleon Press.

Balcazar, Fabricio

2003. "Investigación Acción Participativa (IAP): Aspectos conceptuales y dificultades de implementación".

Fundamentos en Humanidades IV (I y II): 59 - 77.

Cañada, Ernest y Gascón, Jordi

2007. Turismo y Desarrollo. Herramientas para una mirada crítica. Managua: Enlace.

Cañada, Ernest

2015. Las que limpian los hoteles. Barcelona: Icaria. ISBN 9788498886849

Cordero, Allen

2006. Nuevos ejes de acumulación y naturaleza. El caso del turismo. Colección Becas de investigación.

Buenos Aires: CLACSO.

Diez Tetamani, JM y Escudero, Beatriz 2012 Cartografía Social: Investigación e intervención desde las ciencias sociales, métodos y experiencias de aplicación. 1a ed. - Comodoro Rivadavia: Universitaria de la Patagonia, ISBN 978-987-21581-8-7

Espeitx, Elena

2004. Patrimonio alimentario y turismo: una relación singular. PASOS. Revista de Turismo y Patrimonio Cultural, vol. 2, núm. 2, Pp 193-213 España: Universidad de La Laguna

Freire, P.

1969. La educación como práctica de la libertad. Montevideo: Siglo XXI.

Freire, P.

1975. Pedagogía del oprimido. México: Siglo XXI.

11. Freire, P.

1997. ¿Extensión o comunicación? La concientización en el medio rural. México: Siglo XXI.

Funtowicz, Silvio y Strand, Roger

2007. De la demostración experta al diálogo participativo. Revista CTS 8 (3): 97-113.

Goodman, D., Sorj, B. y Wilkinson, J.

1987. From farming to biotechnology: a theory of agro-industrial development.

Oxford, Basil Blackwell.

Guzmán-López, T., Borges, O. y Castillo-Canalejo, A.M.

2011. "Desarrollo económico local y turismo comunitario en países en vías de desarrollo. Un estudio de caso". Revista de Ciencias Sociales (RCS), XVII (3): 432 - 446.

Harris, Roger W.

2009. "Tourism in Bario, Sarawak, Malaysia: A case study of pro-poor community-based tourism integrated into community development”. Asia Pacific Journal of Tourism Research, 14 (2): 125-135.

Lander, Edgardo (Compilador)

2000 La colonialidad del saber: eurocentrismo y ciencias sociales. Perspectivas latinoamericanas. Buenos Aires: CLACSO.

Larsen, J.

2014. "The tourist gaze 1.0, 2.0 and 3.0" . En Lew, Alan A.; Hall, Michael y Williams, Allan (Editores) The Wiley Blackwell Companion to Tourism. Oxford: John Wiley \& Sons.

Leitch, Alison

2010. Slow Food and the politics of pork fat: Italian food and European identity, Ethnos, 68:4, 437-462, DOI: $10.1080 / 0014184032000160514$ 
Lindón, Alicia

2002. "La construcción social del territorio y los modos de vida en la periferia metropolitana." Territorios 7 (Enero): 27-41.

Lindón, Alicia

2007. "Los imaginarios urbanos y el constructivismo geográfico: los hologramas espaciales." EURE 33 (99): 31-46.

Lindón, Alicia

2009. "La construcción socioespacial de la ciudad: el sujeto cuerpo y el sujeto sentimiento" Revista Latinoamericana de Estudios sobre Cuerpos, Emociones y Sociedad (RELACES), ISSN-e 1852-8759, Año 1, No. 1, 2009, Pp. 6-20

Lotti, Ariane

2010. "The commoditization of products and taste: Slow Food and the conservation of agrobiodiversity" Agriculture and Human Values 27(1): 71-83.

López, Ángeles y Marín, Gustavo

2010. "Turismo, capitalismo y producción de lo exótico: Una perspectiva crítica para el estudio de la mercantilización del espacio y la cultura”. Relaciones. Estudios de historia y sociedad XXXI (123): 219-258

Martinez Alier, Joan

2005. El ecologismo de los pobres. Conflictos ambientales y lenguajes de valoración. Barcelona: Icaria-Antrazit

Medina, X.

2017. Reflexiones sobre el patrimonio y la alimentación desde las perspectivas cultural y turística. Anales de Antropología 51 (2): 106-113.

Miele, M. y Murdoch, J.

2002. "The practical aesthetics of traditional cuisines: slow food in Tuscany." Sociologia Ruralis 42 (4): 312-328.

Murdoch, J.

2006. Post-structuralist geography. London: SAGE Publications ltd.

Murphy, P.

1985. Tourism: A community approach. London. Methuen.

Murphy, Peter y Murphy, Ann

2004. Strategic management for tourism communities: Bridging the gaps. Bristol: Channel View Publications.

Nogué, J. y Romero, J.

2006. Las otras geografías. Valencia: Tirant lo Blanch.

Nogué, J.

2014. Sentido del lugar, paisaje y conflicto. Geopolítica(s), vol. 5, núm. 2, 155-163. ISSN: 2172-3958

Pilcher, J.

2008. "Taco Bell, Maseca and Slow Food: A postmodern apocalypse for Mexico's peasant Cuisine". En

Counihan, Carole y Van Esterik, Penny (Editoras) Food and Culture. New York and London: Routledge.

Santos, M.

1996. Metamorfosis del espacio habitado. Barcelona: Oikos-Tau.

Slow Food

s.f. El arca del gusto. Cómo construir el más grande catálogo de los sabores del mundo: un patrimonio a descubrir y a salvar. Recuperado de www.slowfoodfoundation.com/filemanager/.../SPA_libretto_arca_b.pd Spivak, Gayatri

2009. ¿Pueden hablar los subalternos?. Barcelona: Museu d'Art Contemporani.

Sunyer, Pere y Brenner, Ludger

2011. "Turismo y geografía: lugares y patrimonio natural-cultural de la Argentina." POLIS 7 (1): 177-182. Urry, J.

1990. The Tourist Gaze: Leisure and Travel in Contemporary Societies. London: SAGE Publications.

Urry, J. \& Larsen, J.

2011. The tourist gaze 3.0. London: SAGE. ISBN 1446259927, 9781446259924

Vélez, I., Rátiva, S, y Varela, D.

2012. Cartografía social como metodología participativa y colaborativa de investigación en el territorio afrodescendiente de la cuenca alta del río Cauca. Cuad. Geogr. Rev. Colomb. Geogr., Volumen 21, Número 2, p. 59 - 73, 2012. ISSN electrónico 2256-5442. ISSN impreso 0121-215X. 


\section{Notas}

1 La recuperación de semillas es una práctica político-cultural destinada a la conservación y recuperación de las semillas ocupadas tradicionalmente al interior de una familia y/o comunidad. Arrastra un discurso político de rechazo a la manipulación y capitalización de estas, siendo a su vez una práctica campesina y solidaria de autoabastecimiento denominada tranfkintu, la cual ocupa un lugar importante dentro de las prácticas sociales mapuche, siendo celebrados constantemente por las comunidades. 